JTRM | Vol. 3 | No. 1 | Tahun 2021

ISSN (P): 2715-3908 |ISSN (E): 2715-016X

DOI: HTTPS://DOI.ORG/10.48182/JTRM.V3I1.72

\title{
Perawatan Dan Perbaikan Sistem Hidrolik pada Dumping Dump Truck Mitsubishi Fuso 190Ps
}

\author{
Fajri Alrazzak ${ }^{1}$, Jeri Mahyuda ${ }^{2}$, Menhendry $^{3}$, Zulfikar $^{4}$ \\ ${ }^{1}$ Jurusan Teknik Mesin, Program Studi Teknik Manufaktur, Politeknik Negeri Padang \\ 2,3,4 Jurusan Teknik Mesin, Politeknik Negeri Padang
}

Email: fajri.14071998@gmail.com

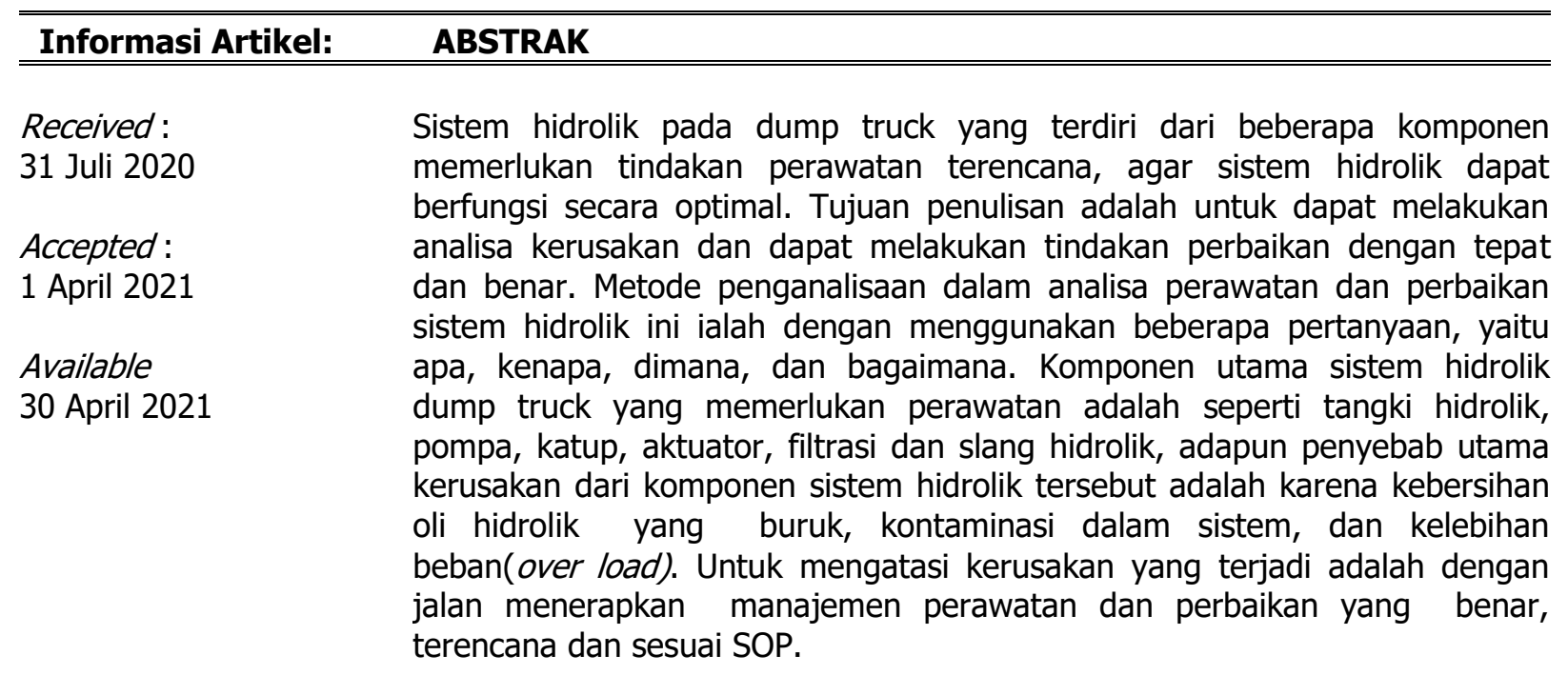

\begin{tabular}{|c|c|}
\hline Kata Kunci: & ABSTRACT \\
\hline Dump Truck & The hydraulic system in a dump truck that consists of several components \\
\hline Dumping & requires a planned maintenance action, so that the hydraulic system can \\
\hline Hidrolik System & function optimally. The purpose of writing is to be able to do damage \\
\hline Maintenance & analysis and can take corrective actions appropriately and correctly. The \\
\hline Excavators & $\begin{array}{l}\text { analysis method in the analysis of maintenance and repair of hydraulic } \\
\text { systems is to use several questions, namely what, why, where and how. The } \\
\text { main components of dump truck hydraulic systems that require maintenance } \\
\text { are hydraulic tanks, pumps, valves, actuators, filtration and hydraulic hose, } \\
\text { while the main causes of damage from hydraulic system components are due } \\
\text { to poor hydraulic oil cleanliness, contamination in the system, and overload } \\
\text { (over load). To overcome the damage that occurs is by implementing } \\
\text { management of care and repair that is correct, planned and in accordance } \\
\text { with the SOP. }\end{array}$ \\
\hline
\end{tabular}

jtrm.polman-bandung.ac.id 


\section{Pendahuluan}

Dengan semakin meningkatnya industri pertambangan, perkebunan maupun konstruksi sipil, maka pemanfaatan alat-alat berat semakin meningkat. Berbagai jenis alat berat yaitu seperti: Exacavator, Dump truck, Bulldozer dan sebagainya, dengan menggunakan alat ini dapat mempermudah kerja manusia karena alat ini telah dilengkapi oleh teknologi yang canggih.

Salah satu alat berat yang yang paling banyak digunakan industri saat ini adalah dump truck untuk mengangkut barang-barang atau hasil pertambangan dari area eksplorasi ke area pengolahan. Dump truck memiliki beberapa komponen utama salah satunya sistem hidrolik untuk mengangkat dan menurunkan dump. Sistem hidrolik pada alat-alat berat juga mengalami perkembangan mulai dengan sistem sederhana yang memiliki pengaturan yang rumit dan sekarang sistem hidrolik telah menggunakan komponen canggih dengan perangkat elektronik untuk peningkatan kepresisian dan memudahkan operator dalam pengoperasiannya.

Komponen utama dalam sistem hidrolik yaitu pompa, katup dan actuator, filtrasi sebagai komponen pendukung. Sistem hidrolik pada dump truck perlu perawatan supaya kemampuan sistem ini dapat berfungsi secara optimal. Sedangkan kerusakan pada sistem hidolik dapat terjadi pada komponen utama seperti pompa, katup dan actuator yang dapat diakibatkan oleh kebersihan cairan yang buruk, kontaminasi, serpihan abrasive, filtarasi buruk dan tidak berfungsi, debu, beban kerja yang berlebih, dan berbagai factor lainnya. Untuk mencegah kerusakan-kerusakan seperti itu perlu pengontrolan dan manajemen perawatan yang benar dan ditangani oleh teknisi yang berpangalaman.

Berdasarkan permasalahan di atas maka perlu dilakukan "Perawatan Dan Perbaikan Sistem Hidrolik Dumping Dump Truck Mitsubishi Fuso 190Ps", untuk menjaga agar proses kerja berlangsung dengan aman dan umur pakai alat lebih panjang.

\section{METODE PENELITIAN}

Penelitian ini dilakukan pada bulan Juni sampai September 2014. Adapun langkah-langkah penelitian yang dapat dilakukan yaitu penelitian untuk proses perawatan dan perbaikan ataupun troubleshooting pada engine. Langkah-langkah penelitian yaitu sebagai berikut:

1. Mengumpulkan informasi (data awal)

2. Mencatat kemungkinan penyebab terjadinya overheating

3. Memeriksa engine secara visual

4. Memperkirakan semua kemungkinan penyebab kerusakan

5. Melakukan pengetesan / uji performance

6. Memastikan penyebab permasalahan

7. Memperbaiki kerusakan

8. Menganalisa mengapa problem bisa terjadi

Agar proses penelitian berjalan dengan lancar dan sesuai dengan proses yang seharusnya, maka dibuatkan langkah kerja sesuai diagram alir pada Gambar 1. 
Sistem Hidrolik pada Dumping Dump Truck Mitsubishi Fuso 190Ps

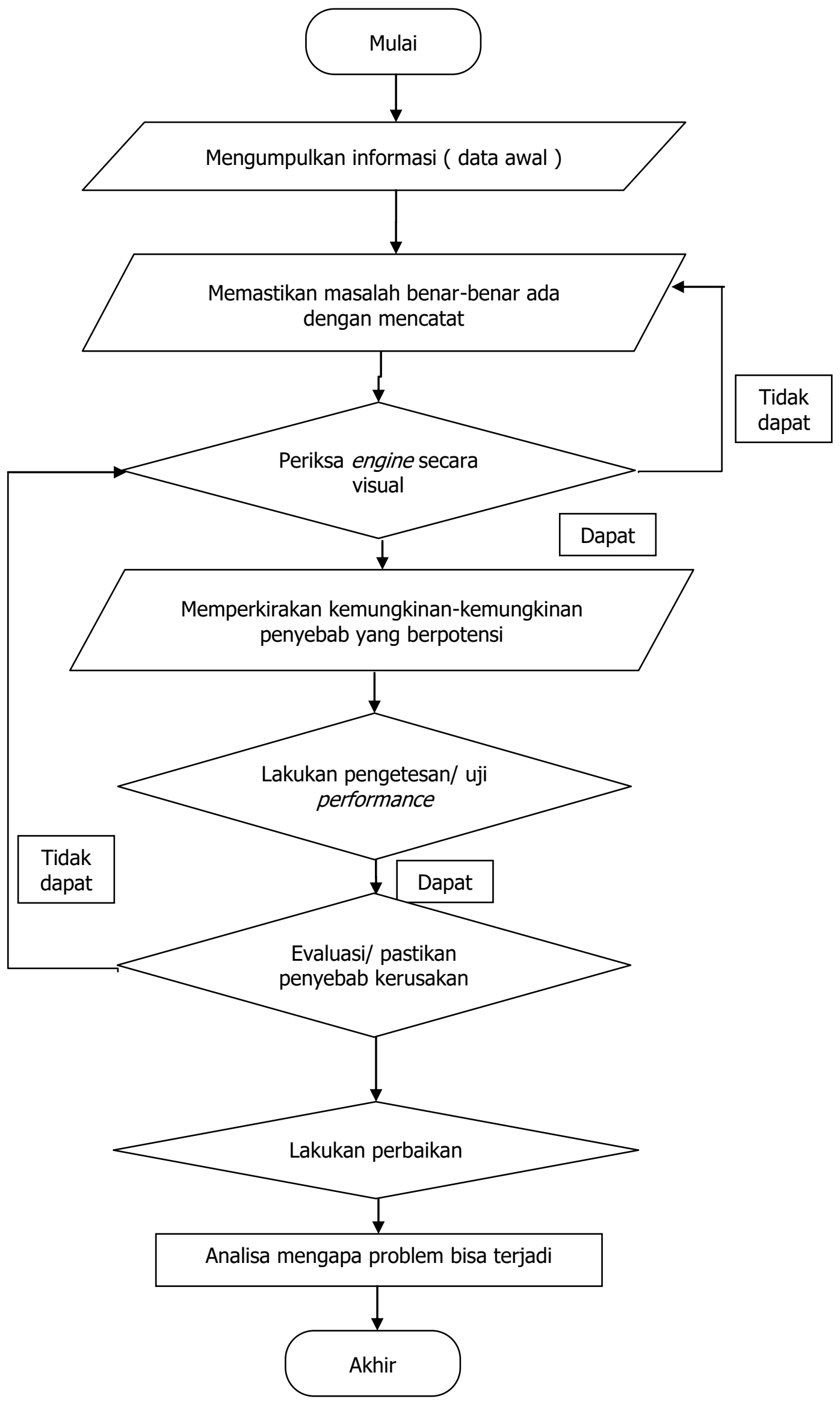

Gambar 1. Diagram alir proses Perawatan dan Perbaikan 


\section{HASIL DAN PEMBAHASAN}

\subsection{Penyebab Terjadinya Kerusakan}

Adapun penyebab utama kerusakan pada sistem hidrolik adalah:

1. Kebersihan oli hidrolik yang buruk

2. Kontaminasi dalam sistem

3. Kelebihan beban (Over Load)

\section{1) Kebersihan Oli Hidrolik yang Buruk}

Kebersihan cairan yang buruk akan menyebabkan bertambahnya jumlah partikel abrasif di dalam cairan hidrolik dari waktu kewaktu. Ada dua jenis partikel yang akan mengganggu sistem hidrolik yaitu partikel aus abrasif dari komponen sistem yang timbul karena keausan normal pada sistem hidrolik sebagaimana terlihat pada Gambar 2. Sebagian partikel ini bersifat relatif lunak seperti misalnya kuningan, sedangkan partikel besi dan baja yang lebih keras menyebabkan percepatan keausan abrasif yang menghasilkan lebih banyak lagi partikel dengan laju yang lebih cepat.

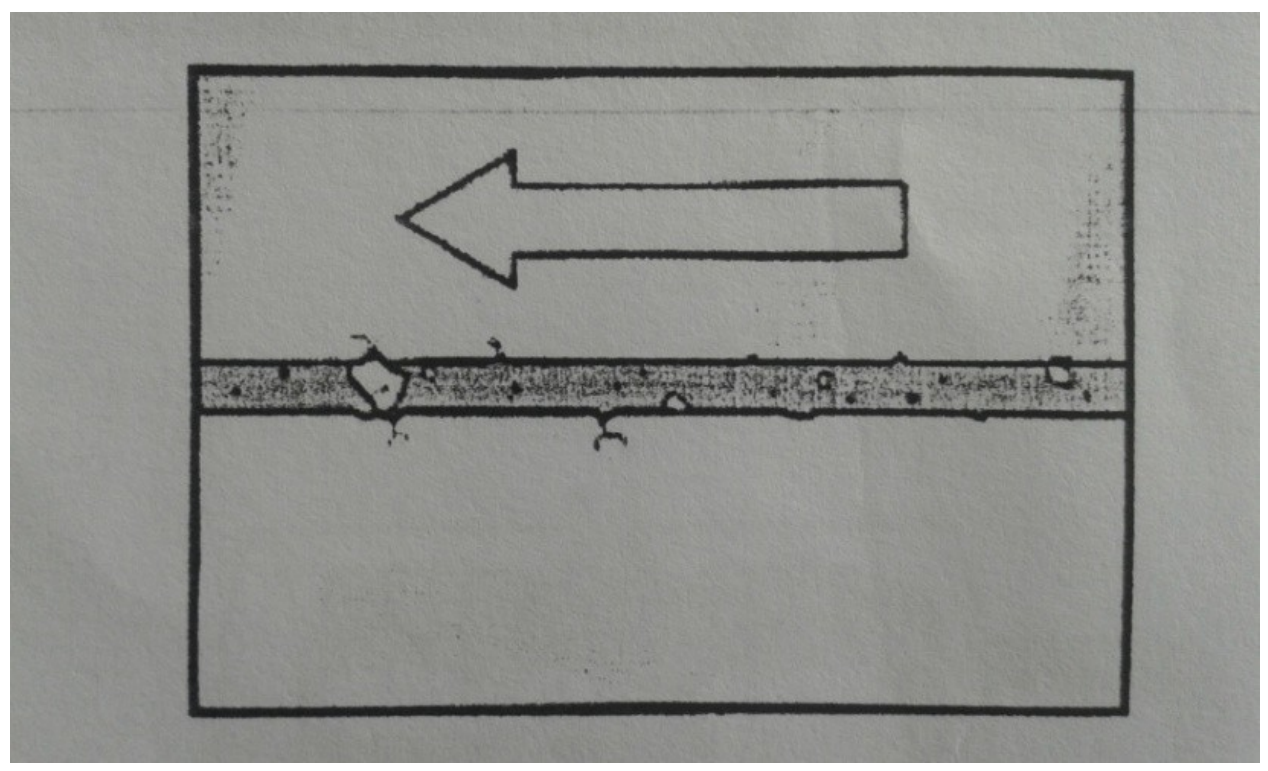

Gambar 2. Partikel aus abrasif

Partikel lain yang mengganggu yaitu partikel debu dari udara yang masuk kedalam tangki hidrolik. Sumber kontaminasi sistem hidrolik yang sering sekali terabaikan adalah debu yang masuk melalui saluran masuk tangki hidrolik yang dapat dilihat pada Gambar 3. Apabila saluran efisiensi tinggi tidak digunakan debu akan terhisap kedalam tangki bersama dengan udara, sebagian dari debu ini akan menempel pada oli atau sisi yang basah pada tangki hidrolik, debu ini akan tetap tertinggal meskipun udara didorong keluar dan akan meningkatkan kontaminasi oli. 


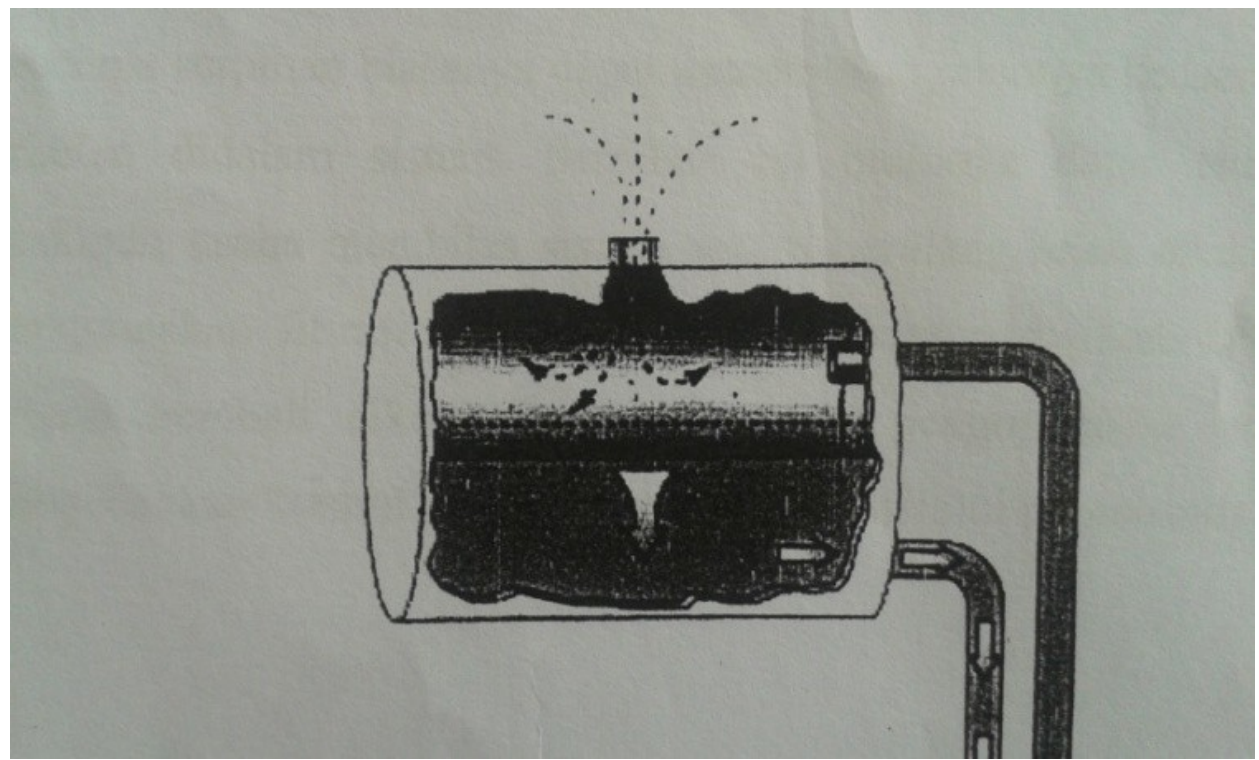

Gambar 3. Partikel debu dan udara yang masuk kedalam tangki

2) Kontaminasi dalam Sistem

Kontaminasi yang parah dalam sistem terjadi sewaktu pompa atau actuator mengalami kerusakan katastropik dan melepaskan serpihan dalam jumlah yang besar kedalam oli hidrolik, partikel ini biasanya berupa baja dan besi yang bersifat sangat keras. Partikel ini dapat bergerak atau mengalir melalui oli hidrolik dan dapat bergerak kedalam katup kontrol dan menyebabkan permasalahan operasional, atau melalui pompa dan actuator sehingga menyebabkan kerusakan tambahan dan bahkan serpihan dalam jumlah yang banyak.

\section{3) Kelebihan Beban}

Kelebihan beban sangat berpengaruh dalam sistem hidrolik, kelebihaan beban merupakan kapasitas kerja mesin atau sistem hidrolik melebihi dari daya kerja sistem hidrolik itu sendiri sehingga kerja mesin atau sistem hidrolik menjadi terpaksa, bila hal ini dibiarkan dalam jangka waktu yang panjang maka kerusakan akan lebih parah dan akan mengakibatkan kerusakan pada seluruh komponen.

\subsection{Penyebab-penyebab Permasalahan Pada Tangki Hidrolik dan Cara Mengatasinya}

Biasanya kerusakan yang terjadi pada tangki hidrolik adalah dikarenakan kebersihan yang kurang, karat dan terjadinya kebocoran pada tangki hidrolik. Cara mengatasi kerusakan tersebut adalah dengan cara seperti berikut:

1) Jangan lupa membersihkan tangki hidrolik dari debu dan kotoran yang menempel pada tangki hidrolik.

2) Apabila terjadi perkaratan lakukan pengikisan dan pengamplasan pada tangki hidrolik kemudian lakukan pengecatan untuk mencegah terjadinya perkaratan lagi.

3) Apabila terjadinya kebocoran pada tangki hidrolik biasanya lakukan penambalan pada tangki hidrolik dengan cara pengelasan dengan las gas atau las karbit, apabila cara mengatasi dengan las gas tidak bisa maka ganti tangki hidrolik dengan yang baru. 


\subsection{Penyebab-penyebab Kerusakan Pompa Roda Gigi dan Cara Mengatasinya}

Adapun penyebab kerusakan pada pompa hidrolik yang dapat dilihat pada Gambar 4 adalah sebagai berikut:

1) Apabila kualitas cairan oli kurang bersih maka akan dapat menyebabkan pompa roda gigi cepat haus dan tidak akan bertahan lama.

2) Membesarnya celah atau terjadinya kelonggaran antara roda gigi dan rumah pompa yang terjadi akibat keausan bantalan.

3) Kerusakan pada rumah pompa akan meningkatkan kebocoran internal yang mengakibatkan kurangnya aliran keluar.

4) Serpihan abrasif yang terjebak dalam celah antara roda gigi dan rumah pompa yang dapat menyebabkan kerusakan pada roda gigi dan rumah pompa tersebut.

Cara mengatasi keausan dan kerusakan pada pompa roda gigi tersebut adalah:

1) Memeriksa minyak atau oli hidrolik yang digunakan, jumlahnya, sifat-sifat oli yang mungkin telah dipengaruhi oleh masa kerjanya. Selanjutnya disesuaikan dengan standart atau diganti dengan yang baru dengan tipe dan viscositas yang sesuai dengan spesifikasinya.

2) Bila terjadi kelonggaran pada bantalan roda gigi segera ganti bantalan roda gigi atau bering dengan yang baru juga ganti sea/ dengan yang baru.

3) Bila terjadi kerusakan pada rumah pompa maka bersihkan pompa dari kotoran, dan apa bila terjadi kebocoran pada pompa segera lakukan penambalan dengan las gas apa bila cara tersebut tidak efisien maka ganti rumah pompa dengan yang baru.

4) Apabila serpihan abrasif sudah banyak dalam pompa lakukan service ringan pada pompa untuk membersihkan dalam pompa dari serpihan abrasif, juga periksa ada tidaknya hambatan pada katup-katup saluran, dan juga memeriksa saringan filter yang tersumbat atau kotor.

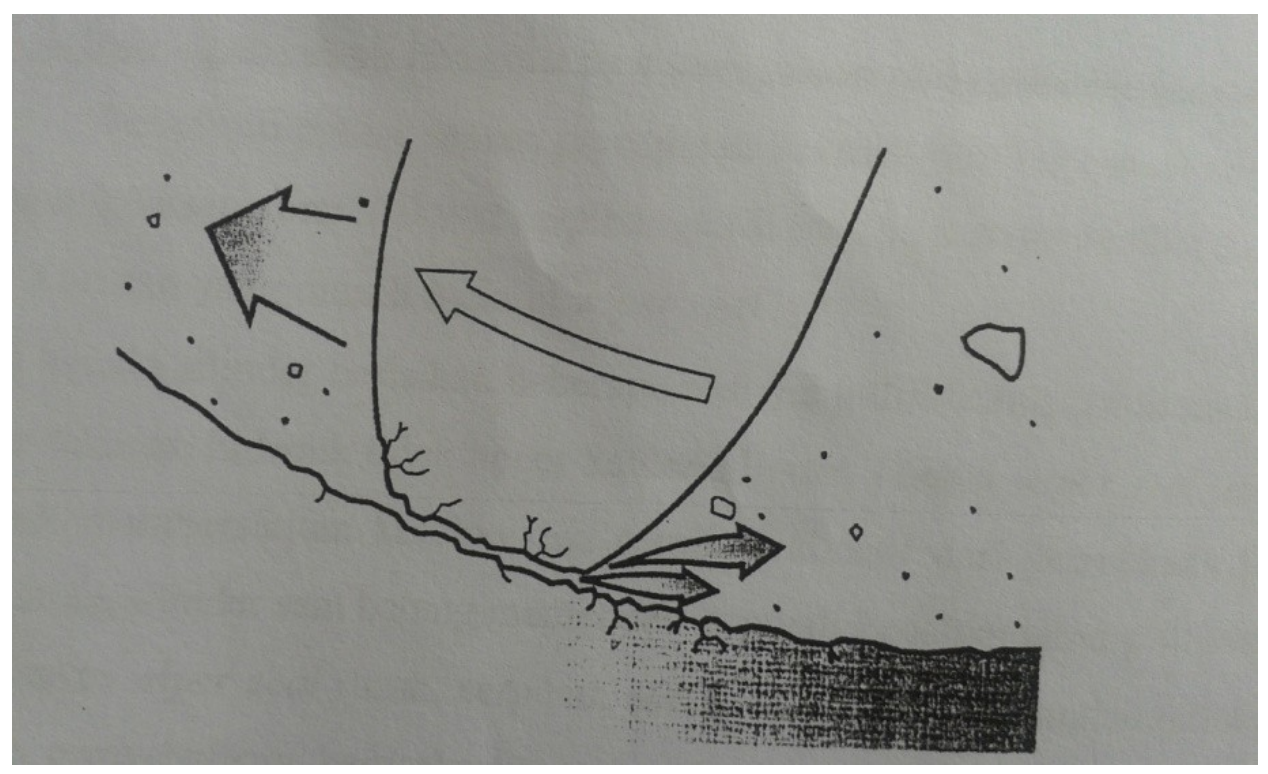

Gambar 4. Serpihan yang merusak roda gigi

\section{4 Penyebab Kerusakan Pada Katup Hidrolik dan Cara Mengatasinya}

Salah satu permasalahan yang terjadi pada katup hidrolik adalah tersendat atau tudak berfungsi katup tersebut biasanya ini disebabkan karena serpihan abrasif dan juga karena 
keausan katup tersebut. Cara mengatasinya adalah dengan melakukan pembongkaran dan pembersihan katup dan apa bila ada bagian komponen yang rusak dan harus diganti lakukan penggantian, ini biasanya terjadi pada seal katup.

\section{5 Penyebab-penyebab Keausan Dan Kerusakan Pada Silinder Hidrolik}

Penyebab yang paling umum percepatan keausan dan kerusakan silinder hidrolik adalah keausan abrasif akibat serpihan, tetapi ada juga hal lain yang menyebabkan kerusakan pada silinder hidrolik, ada beberapa penyebab kerusakan pada silinder hidrolik adalah sebagai berikut:

1) Kurangnya kebersihan pada silinder hidrolik, ini juga berakibat terjadinya percepatan kerusakan pada silinder hidrolik.

2) Kotoran yang masuk melalui wiper seal

Sisi kepala silinder berisikan beberapa seal yang dirancang untuk menjaga agar tekanan hdrolik tidak bocor keluar silinder. Fungsi wiper seal adalah untuk membersihkan kotoran dan serpihan abrasive dari permukaan licin dari batang silinder saat batang silinder memendek kembali kedalam tabung silinder, sewaktu wiper seal rusak serpihan abrasif dan kotoran lain akan dengan mudah tertanam dan akan menyebabkan kegoresan pada batang silinder dan akan menyebabkan kebocoran., apa bila tidak dicegah dengan segera kerusakan ini akan bertambah parah.

3) Serpihan abrasif akibat kerusakan pompa

Kerusakan pada pompa menyebabkan serpihan abrasif, serpihan ini akan masuk ke dalam sistem hidrolik melalui tekanan oli yang diberikan pompa sehingga serpihan tersebut juga bisa merusak silinder hidrolik.

4) Kelebihan beban(over load)

Kelebihan beban disebabkan oleh daya kerja sistem hidrolik melebihi kerja dari sistem hidrolik tersebut, ini akan menyebabkan kerusakan pada silinder hidrolik, akan tetapi tidak hanya pada silinder hidrolik saja terjadi kerusakan yang disebabkan oleh kelebihan beban, tetapi semua komponen hidrolik juga bisa mengalami kerusakan karena kerja yang berlebih terutama pompa hidrolik.

Cara mengatasi kerusakan pada silinder hidrolik:

Apabila terjadi kerusakan pada wiper seal maka lakukan penggantian dengan wiper seal yang baru, denga cara sebagai berikut:

i. Langkah awal dengan cara menaikan dump pada kendaraan, beri bantalan pada bawah dump tersebut agar saat melepas boom, dump tidak jatuh.

ii. Buang angin pada silnder hidrolik atau boom agar saat membuka silnder, oli tidak menyembur keluar.

iii. Lepaskan as silinder dari dump yang terlebih dahulu silinder diikat dengan katrol agar saat penurunan lebih mudah.

iv. Lepas slang hidrolik dari silinder hidrolik

v. Kemudian buka kepala tabung silinder dengan menggunakan kunci $L$, tetapi ini juga tergantung baut yang digunakan.

vi. Kemudian keluarkan silinder hidrolik, setelah itu ganti wiper seal yang lama dengan yang baru, akan tetapi periksa terlebih dahulu kerusakan yang lain.

vii. Kemudian pasang kembali bagian-bagian silinder hidrolik atau boom yang dilepas tadi. 
viii. Setelah semuanya terpasang lakukan pengetesan pada silinder hidrolik tersebut,dan lakukan pengecekan pada wiper seal apakah masih terjadi kebocoran atau tidak.

i) Apabila terdapat banyak serpihan abrasif didalam tabung hidrolik atau pada sistem hidrolik adalah dengan cara mengganti cairan hidrolik dengan tipe dan viscositas yang telah ditentukan, juga mengganti saringan hidrolik.

Adapun cara mengatasi kerusakan pada silinder hidrolik adalah dengan cara menentukan banyak jam kerja seperti berikut :

\section{Setiap 10 jam kerja atau harian}

a. Periksa tingkat oli pada tangki hidrolik dengan menggunakan tongkat pengukur oli hidrolik, jika oli berkurang lakukan penambahan pada oli hidrolik, tingkat oli juga bisa dilihat pada oil pressure hidrolic gauge yang biasanya terletak di dask boor kendaraan dan oli harus berada pada tanda full.

b. Bersihkan komponen-komponen dari kotoran-kotoran yang menempel.

\section{Setiap 250 jam kerja atau bulanan}

a. Bersihkan komponen-komponen dari kotoran-kotoran yang menempel yang akan menyebabkan kerusakan terutama pada bagian yang akan merusak silinder hidrolik dan juga pada wiper seal.

b. Lumasi dua fittings pada setiap sisi silinder hidrolik, total terdapat empat buah fittings pada silinder hidrolik tersebut. ini bertujuan untuk mengurangi keausan pada as silinder hidrolik.

c. Lakukan juga pengecekan pada oli hidrolik.

\section{Setiap 1000 jam kerja atau 6 bulanan}

a. Bersihkan komponen-komponen hidrolik dari kotoran-kotoran yang menempel.

b. Apa bila terjadi kelongaran pada bantalan pompa maka lakukan serfis dan perbaikan pada pompa hidrolik terutama pada bantalan pompa, karena ini juga akan berpengaruh pada kerja silinder hidrolik.

c. Periksa kebocoran pada katup hidrolik, apa bila terjadi kebocoran segera lakukan pergantian sea/ pada katup hidrolik.

d. Periksa kebocoran pada slang hidrolik dan juga kelonggaran pada baut slang hidrolik, bila terjadi kelonggaran maka lakukan pengencangan pada baut, dan jika terjadi kebocoran segera ganti slang dengan yang baru.

e. Ganti filter hidrolik dengan yang baru apa bila filter yang lama sudah tidak layak pakai lagi, karena filter berperan sangat penting dalam penyaringan serpihan-serpihan abrasif.

f. Lakukan pengecekan pada silinder hidrolik baik pada seal, batang silinder, dan pada rumah silnder, apa bila terjadi kerusakan maka segera lakukan perbaikan dan penggantian pada komponen-komponen yang rusak tersebut, biasanya komponen yang sering rusak adalah pada wiper seal.

g. Apa bila telah banyak terdapat serpihan-serpihan abrasif pada oli hidrolik segera lakukan penggantian pada oli hidrolik yang sesuai dengan tipe dan viscositas yang telah ditentukan.

\section{6 Penyebab-penyebab Kerusakan Pada Filtrasi Hidrolik dan Cara Mengatasinya}

Penyebab kerusak pada filtrasi pada sistem hidrolik adalah karena serpihan-serpihan abrasif yang bercampur dengan oli hidrolik, dan juga karena kontaminasi dalam sistem hidrolik.

Cara mengatasinya adalah dengan cara sebagai berikut: 
1) mengganti saringan filtrasi dengan yang baru agar serpihan abrasif dapat disaring dengan sempurna dan tidak akan menyebabkan kerusakan pada komponen-komponen lainnya.

2) Menganti oli hidrolik yang telah bercampur dengan serpihan abrasif dan kotoran lainnya.

\section{7 Penyebab-penyebab Kerusakan Pada Pipa Hidrolik dan Cara Mengatasinya}

Adapun penyebab-penyebab kerusakan pada pipa hidrolik adalah sebagai berikut :

a. Kebersihan pipa atau slang hidrolik yang kurang sehingga mengakibatkan pipa menjadi lapuk dan terjadi retakan pada pipa atau slang hidrolik.

b. Terjadinya patahan pada pipa atau slang hidrolik yang disebabkan oleh terjepitnya slang tersebut.

c. Tidak adanya slang hidrolik diberi batas regang dan batas kendur.

Cara mengatasinya adalah sebagai berikut:

a. Lakukan pembersihan pada pipa atau slang hidrolik dari debu dan kotoran-kotoran lain yang menempel pada slang hidrolik, biasanya kotoran yang menempel pada slang hidrolik adalah debu yang telah bercampur dengan oli hidrolik yang bocor dan mengalir pada slang hidrolik.

b. Lakukan pengecekan pada slang hidrolik apakah ada slang yang terjepit oleh dump atau oleh rumah silinder hidrolik ataupun penyebab lainnya.

c. Dengan memberikan batas regang dan batas kendur pada slang hidrolik

\section{KESIMPULAN}

Kesimpulan yang dapat diambil dari kegiatan perawatan dan perbaikan yang sudah dilakukan pada Dumping Dump Truck Mitsubishi Fuso 190Ps adalah sebagai berikut: Pada umumnya kerusakan yang terjadi pada sistem hidrolik disebabkan karena kebersihan oli hidrolik yang buruk akibat partikel abrasive, uap air, dan debu yang masuk kedalam tangki, kontaminasi dalam sistem akibat kotoran yang masuk melalui wiper sealyang rusak, dan kelebihan beban ( over load) akibat tekanan pompa lebih rendah dari tekanan beban yang harus digerakkan oleh actuator. Cara mengatasi kerusakan yaitu dengan melakukan pengecekan terlebih dahulu pada oli hidrolik dan lakukan pembersihan pada saluran tangki oli hidrolik sebelum memasukkan oli hidrolik kedalam tangki. Membongkar pompa untuk mengganti gigi pompa hidrolik yang mengalami kerusakan katastropik, mengganti filter hidrolik, dan mengganti oli hidrolik dengan yang baru dan sesuai dengan viscositas yang telah ditentukan, juga mengganti wiper seal dengan yang baru. Untuk mengatasi kelebihan beban perlu mengangkat beban yang tidak berlebih dan sesuai dengan standar yang telah ditentukan, lakukan pengecekan pada pompa, katup, dan slang hidrolik dan ganti bagian yang rusak.

\section{REFERENSI}

1) https://www.truckmagz.com/sistem-hidrolik-pada-dump-truck/

2) http://eprints.ums.ac.id/57923/23/NASKAH\%20PUBLIKASI.pdf

3) https://www.alibaba.com/trade/search?fsb=y\&IndexArea=product_en\&CatId=\&SearchTe $\mathrm{xt}=$ travel + motor+morooka\&viewtype $=\mathrm{G}$, diunduh 14 April 2020

4) 2017http://www.crawlercarriersales.com/brochures/maintenance/info_18.html, diunduh 14 April 2020 
5) 2017 Http://www.sgmorris.com/wp-content/upload/5-Pump-Failur-Analysis.pdf,diunduh 14 April 2020

6) Didik Setiawan, (2015) Analisa Hidrolik Sistem Lifter Pada Farm Tractor Foton FT 824, Universitas Muhammadiya Surakarta

7) Morooka, 2005. Service Manual MST Series Rubber crawler Carrier. Japan

8) Morooka, 2005. Part List Rubber crawler Carrier MST-600VD. Japan

9) Vokasi, T. P. (2013). Basic Trouble Shooting.Surakarta: Sekolah Vokasi

10) Vokasi, T. P. (2013). Hydraulic System.Surakarta: Sekolah Vokasi 